\title{
MRI surveillance for the detection of local recurrence in rectal cancer after transanal endoscopic microsurgery
}

Citation for published version (APA):

Hupkens, B. J. P., Maas, M., Martens, M. H., Deserno, W. M. L. L. G., Leijtens, J. W. A., Nelemans, P. J., Bakers, F. C. H., Lambregts, D. M. J., Beets, G. L., \& Beets-Tan, R. G. H. (2017). MRI surveillance for the detection of local recurrence in rectal cancer after transanal endoscopic microsurgery. European Radiology, 27(12), 4960-4969. https://doi.org/10.1007/s00330-017-4853-5

Document status and date:

Published: 01/12/2017

DOI:

10.1007/s00330-017-4853-5

Document Version:

Publisher's PDF, also known as Version of record

Document license:

Taverne

Please check the document version of this publication:

- A submitted manuscript is the version of the article upon submission and before peer-review. There can be important differences between the submitted version and the official published version of record.

People interested in the research are advised to contact the author for the final version of the publication, or visit the DOI to the publisher's website.

- The final author version and the galley proof are versions of the publication after peer review.

- The final published version features the final layout of the paper including the volume, issue and page numbers.

Link to publication

\footnotetext{
General rights rights.

- You may freely distribute the URL identifying the publication in the public portal. please follow below link for the End User Agreement:

www.umlib.nl/taverne-license

Take down policy

If you believe that this document breaches copyright please contact us at:

repository@maastrichtuniversity.nl

providing details and we will investigate your claim.
}

Copyright and moral rights for the publications made accessible in the public portal are retained by the authors and/or other copyright owners and it is a condition of accessing publications that users recognise and abide by the legal requirements associated with these

- Users may download and print one copy of any publication from the public portal for the purpose of private study or research.

- You may not further distribute the material or use it for any profit-making activity or commercial gain

If the publication is distributed under the terms of Article $25 \mathrm{fa}$ of the Dutch Copyright Act, indicated by the "Taverne" license above, 


\title{
MRI surveillance for the detection of local recurrence in rectal cancer after transanal endoscopic microsurgery
}

\author{
Britt J. P. Hupkens ${ }^{1,2,3}$ • Monique Maas ${ }^{1,4}$ (i) - Milou H. Martens ${ }^{1,2,3}$. \\ Willem M. L. L. G. Deserno ${ }^{5}$ • Jeroen W. A. Leijtens ${ }^{6}$ • Patty J. Nelemans ${ }^{7}$ • \\ Frans C. H. Bakers ${ }^{1,8}$ • Doenja M. J. Lambregts ${ }^{9}$ - Geerard L. Beets ${ }^{3,10}$. \\ Regina G. H. Beets-Tan ${ }^{3,9}$
}

Received: 4 October 2016/Revised: 29 March 2017 / Accepted: 12 April 2017 /Published online: 30 June 2017

(C) European Society of Radiology 2017

\begin{abstract}
Objectives To evaluate diagnostic performance of follow-up MRI for detection of local recurrence of rectal cancer after transanal endoscopic microsurgery (TEM).

Methods Between January 2006 and February 2014, 81 patients who underwent TEM were included. Two expert readers (R1 and R2), independently evaluated T2-weighted (T2W) MRI and diffusion-weighted (DWI) MRI for the detection of local recurrence, retrospectively, and recorded confidence on a five-point scale. Diagnostic performance of follow-up MRI was assessed using ROC-curve analysis and kappa statistics for the reproducibility between readers.

Results 293 MRIs were performed, 203 included DWI. 18 (22\%) patients developed a local recurrence: luminal 11, nodal two and both five. Areas under the curve (AUCs) for local recurrence detection were 0.72 (R1) and 0.80 (R2) for T2WMRI. For DWI, AUCs were 0.70 (R1) and 0.89 (R2). For nodal recurrence AUCs were $0.72(\mathrm{R} 1)$ and $0.80(\mathrm{R} 2)$ for
\end{abstract}

Electronic supplementary material The online version of this article (doi:10.1007/s00330-017-4853-5) contains supplementary material, which is available to authorized users.

Monique Maas

moniquemaas@live.nl

1 Department of Radiology, Maastricht University Medical Center, Maastricht, The Netherlands

2 Department of Surgery, Maastricht University Medical Center, Maastricht, The Netherlands

3 GROW School for Oncology and Developmental Biology, Maastricht, The Netherlands

4 Department of Radiology, The Netherlands Cancer Institute, Plesmanlaan 121, 1066 CX Amsterdam, The Netherlands
T2W-MRI. Reproducibility was good for T2W-MRI ( $\mathrm{k} 0.68$ for luminal and $\kappa 0.71$ for nodal recurrence) and moderate for DWI ( $\mathrm{k} 0.57)$. AUCs and reproducibility for recurrence detection increased during follow-up.

Conclusions Follow-up with MRI after TEM for rectal cancer is feasible. Postoperative changes can be confusing at the first postoperative MRI, but during follow-up diagnostic performance and reproducibility increase.

Key Points

- Follow-up with MRI is feasible for follow-up after TEM for rectal cancer.

- DWI-MRI is a useful addition to detect recurrences after TEM.

- Postoperative changes can be confusing and can lead to underestimation of recurrence.

- Appearance of intermediate signal at T2W-MRI is suspicious for recurrence.

- Nodal staging remains challenging.
5 Department of Radiology, Laurentius Hospital, Roermond, The Netherlands

6 Department of Surgery, Laurentius Hospital, Roermond, The Netherlands

7 Department of Epidemiology, Maastricht University, Maastricht, The Netherlands

8 Maastricht University Medical Centre, Maastricht, The Netherlands

9 Department of Radiology, The Netherlands Cancer Institute, Amsterdam, The Netherlands

10 Department of Surgery, The Netherlands Cancer Institute, Amsterdam, The Netherlands 
Keywords Magnetic resonance imaging - Rectal neoplasms · Transanal endoscopic microsurgery $\cdot$ Follow-up .

Diffusion-weighted magnetic resonance imaging

$\begin{array}{ll}\text { Abbreviations } \\ \text { ADC } & \text { Apparent diffusion coefficient } \\ \text { AUC } & \text { Area under the curve } \\ \text { CI } & \text { Confidence interval } \\ \text { CL } & \text { Confidence level } \\ \text { CRT } & \text { Chemoradiation therapy } \\ \text { DWI } & \text { Diffusion-weighted imaging } \\ \text { ERUS } & \text { Endorectal ultrasound } \\ \text { MRI } & \text { Magnetic resonance imaging } \\ \text { ROC curve } & \text { Receiver operating characteristic curve } \\ \text { T2W-MRI } & \text { T2-weighted MRI } \\ \text { TEM } & \text { Transanal endoscopic microsurgery }\end{array}$

\section{Introduction}

Transanal endoscopic microsurgery (TEM) is used for the treatment of early rectal cancer, e.g. resection of adenomas and T1sm1 tumours [1,2]. Recently, TEM has been proposed as an alternative for total mesorectal excision (TME) in small residual tumours after neoadjuvant treatment, in line with the increasing interest for organ preservation after neoadjuvant treatment $[3,4]$. Reported recurrence rates are in the range of $0-24 \%$ for early rectal cancer treated by local excision or TEM [5-11] and 7-14\% for TEM after neoadjuvant treatment [4]. Recurrence of early rectal cancer after TEM depends on the primary features of the tumour, e.g. tumour stage, Sminvasion and differentiation grade [1]. Recurrences in patients after chemoradiation usually occur within the first 18 months of follow-up and consist of luminal rather than nodal recurrences $[3,12,13]$.

The increased use of TEM stresses the need for an accurate follow-up tool to assess local status and to identify both luminal and nodal recurrences. The mainstay of follow-up has been endoscopy with endorectal ultrasound (ERUS). MRI can assess both the lumen and the mesorectum and is less operator dependent than ERUS [14, 15]. Therefore, MRI is expected to be of additional value for follow-up after TEM [16]. However, so far, no literature exists on the value of MRI in follow-up after TEM.

Therefore, the aim of this study was to evaluate MRI for follow-up after TEM (in patients with and without neoadjuvant treatment) with regard to diagnostic performance for detection of a luminal or nodal recurrence and interobserver agreement.

\section{Material and methods}

\section{Patients}

Institutional review board approval and informed consent were waived for this retrospective study. In total 378 patients were treated between January 2006 and February 2014 with TEM in a regional tertiary referral centre. Study patients had to meet the following inclusion criteria: (1) histologically proven rectal cancer, (2) R0 resection and (3) follow-up with MRI. Patients with histology other than adenocarcinoma were excluded. In total 81 patients fulfilled these criteria. All TEMs were performed in one regional, tertiary TEM referral hospital, according to regional guidelines [17]. The population consisted of two patient groups: (1) patients with small rectal tumours (up to cT2) without (neo)adjuvant therapy and (2) patients with a small residual tumour after neoadjuvant therapy (up to ycT2).

\section{Follow-up}

Follow-up was combined in two hospitals: a regional hospital in which the TEMs were performed, and a university hospital with specific expertise in rectal cancer MRI. Follow-up consisted of three MRIs (at 3, 6 and 12 months of followup) and 3-4 endoscopies in the first year, and two MRIs and two endoscopies (every 6 months) in years $2-5$ [18].

MRI consisted of T2-weighted (T2W) sequences in three orthogonal directions. All scans that were performed at the university hospital included a diffusion-weighted imaging (DWI) sequence. MR sequences per centre are shown in Appendix 1.

\section{MRI evaluation}

All MRIs were evaluated by two independent expert readers (RGHB and MM). Reader 1 (RGHB) (R1) had 20 years of experience and reader $2(\mathrm{MM})(\mathrm{R} 2)$ had 8 years of experience in reading rectal cancer MRI and post-TEM MRI. Presence of a local and/or nodal recurrence was evaluated by means of a 5point confidence level scale (CL0: definitely no recurrence; CL1: probably no recurrence; CL2: indeterminate presence of recurrence; CL3: probable recurrence; CL4: definite recurrence). First, T2W-MRI was evaluated and then - in the same reading session - DWI was evaluated (T2W + DWI). The readers were blinded for endoscopy, histopathology and each other's results. The imaging criteria used to define the confidence level scores are shown in Table 1. Additionally, readers evaluated morphology (normal rectal wall, scar tissue, fibrosis (massive or minimal), oedema), and signal intensity (high, intermediate or low signal) of the rectal wall and the mesorectal tissue on T2W-MRI (Fig. 1). Change in morphology and signal intensity during follow-up were noted. 
Table 1 Definitions of confidence level scores for luminal and nodal recurrences

\begin{tabular}{|c|c|c|c|}
\hline Confidence level & Luminal recurrence on T2W-MRI & Luminal recurrence on DWI-MRI & Nodal recurrence on T2W-MRI [28] \\
\hline $\begin{array}{l}\text { CL0: Definitely no } \\
\text { recurrence }\end{array}$ & $\begin{array}{l}\text { Normal/intact rectal wall } \\
\text { No intermediate signal at } \\
\text { TEM location }\end{array}$ & $\begin{array}{l}\text { Absence of high signal in scar at } \\
\text { b1000 images }\end{array}$ & $\begin{array}{l}\text { - Normal size }(<5 \mathrm{~mm}) \\
\text { - Homogeneity of the nodal } \\
\text { signal } \\
\text { - Oval shape } \\
\text { - Regular border }\end{array}$ \\
\hline $\begin{array}{l}\text { CL1: Probably no } \\
\text { recurrence }\end{array}$ & Minimal fibrotic wall thickening & $\begin{array}{l}\text { No circumscribed foci of high } \\
\text { signal in scar at b1000 images }\end{array}$ & $\begin{array}{l}\text { Normal size }(<5 \mathrm{~mm}) \text { with one of } \\
\quad \text { following criteria: } \\
\text {-Heterogeneous signal in node } \\
\text { - Round shape } \\
\text { - Irregular border }\end{array}$ \\
\hline $\begin{array}{l}\text { CL2: Intermediate } \\
\text { presence of recurrence }\end{array}$ & $\begin{array}{l}\text { Interrupted or defect rectal wall } \\
\text { with mesorectal spiculation } \\
\text { Heterogeneous signal in the scar } \\
\text { Closed rectal wall with massive } \\
\text { fibrosis and mesorectal spiculation }\end{array}$ & $\begin{array}{l}\text { Small foci of high signal in scar at } \\
\text { b1000 images }\end{array}$ & $\begin{array}{l}\text { Normal size }(<5 \mathrm{~mm}) \text { with two } \\
\quad \text { of before mentioned criteria, } \\
\text { OR } \\
\text { Intermediate size }(5-9 \mathrm{~mm}) \text { with } \\
\quad \text { one of before mentioned criteria }\end{array}$ \\
\hline $\begin{array}{l}\text { CL3: Probably } \\
\text { recurrence }\end{array}$ & $\begin{array}{l}\text { Mixed signal intensity, but predominantly } \\
\text { intermediate signal }\end{array}$ & $\begin{array}{l}\text { A small, but obvious area of high } \\
\text { signal in scar at b1000 images }\end{array}$ & $\begin{array}{l}\text { Normal size }(<5 \mathrm{~mm}) \text { with three out } \\
\text { of three criteria } \\
\text { OR } \\
\text { Intermediate size }(5-9 \mathrm{~mm}) \text { with two } \\
\text { of abovementioned criteria }\end{array}$ \\
\hline $\begin{array}{l}\text { CL4: Definitely } \\
\text { recurrence }\end{array}$ & $\begin{array}{l}\text { Massive intermediate signal of rectal wall } \\
\text { or mesorectal tissue }\end{array}$ & $\begin{array}{l}\text { Marked high signal in scar or } \\
\text { mesorectal tissue at b1000 images }\end{array}$ & $\begin{array}{l}\text { Size }>9 \mathrm{~mm} \\
\text { OR } \\
\text { Intermediate size }(5-9 \mathrm{~mm}) \text { with } \\
\quad \text { three out of three criteria }\end{array}$ \\
\hline
\end{tabular}

\section{Reference standard}

The reference standard consisted of histopathology in case of a suspected local (luminal or nodal) recurrence. For a luminal recurrence the histopathological diagnosis was obtained either with a biopsy or with the resection specimen of the re-TEM or TME. In case of a nodal recurrence the reference standard was the TME specimen. For patients without a recurrence follow-up was the reference standard, with a minimal disease-free follow-up time of 15 months considered as absence of recurrence as calculated from the last follow-up MRI that was performed.

\section{Statistical analysis}

Statistical analyses were performed with IBM SPSS version 22 (Chicago, Il, USA) and Stata, Statacorp Stata version 11.0 (College Station, Tx, USA: StataCorp LP 2009). Descriptive analyses were used to assess baseline characteristics. The confidence level scores for luminal and nodal recurrence were used to construct receiver operating characteristic (ROC) curves and areas under the curve (AUCs) were calculated to evaluate diagnostic performance. Cut-off for confidence level score was determined before onset of the study between 2 and 3. AUCs were compared using the method of Hanley et al. [19]. Because patients underwent several MRIs during follow-up, results from the individual MRIs are not independent observations. Therefore, robust variance estimates which adjust for correlation of data within patients were used for calculation of $95 \%$ confidence intervals for sensitivities and specificities [20].

Interobserver agreement was analysed using quadratic weighted kappa coefficients. The degree of agreement was interpreted as follows: poor agreement as $\mathrm{K}$ value $0.00-0.20$; fair agreement as $\mathrm{K}$ value $0.21-0.40$; moderate agreement as $\mathrm{K}$ value $0.41-0.60$; good agreement as $K$ value $0.61-0.80$, and excellent agreement as $\mathrm{K}$ value $0.81-1.00$ [21].

For the analyses of the agreement between readers with regard to the predictive morphological factors, the proportion of specific agreement was calculated for positive and negative outcome by the method proposed by de Vet et al. [22] This method was chosen as an alternative for Cohen's $\mathrm{K}$, as the prevalence of recurrence is very low, leading to an underestimation of the agreement when using Cohen's $\mathrm{k}$ [22].

Diagnostic performance and agreement were calculated for the total group, but also for the first postoperative MRI and subsequent MRIs separately, to evaluate whether diagnostic performance increases during follow-up. With logistic regression analyses imaging factors (based on scoring of morphology and signal intensity of the rectal wall and mesorectum) predictive of recurrence were identified. Odds ratios (ORs) with $95 \%$ confidence intervals (CIs) are reported. $p$-values $\leq 0.05$ were considered statistically significant. 

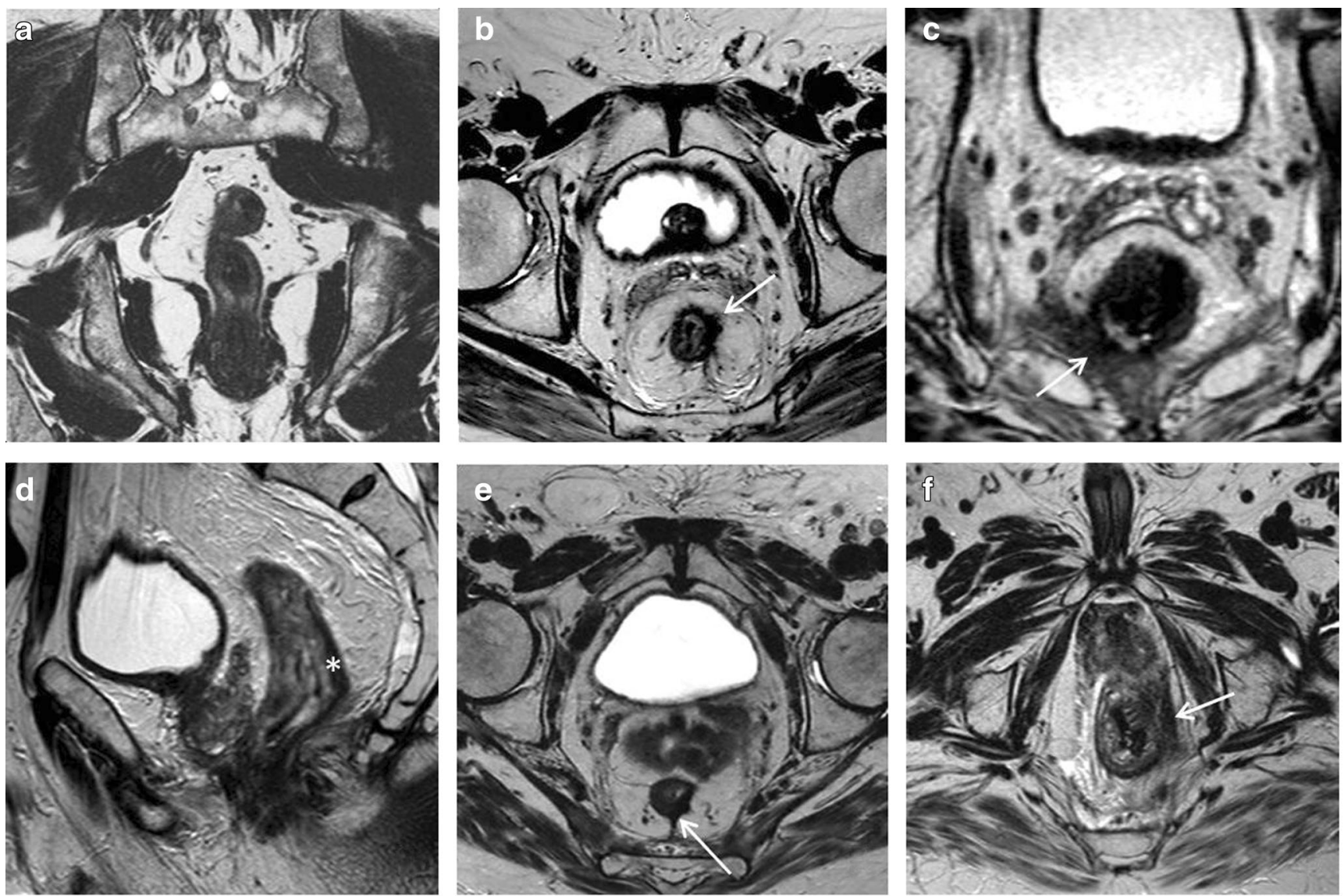

Fig. 1 Examples of morphological changes in the rectal wall and mesorectal tissue after transanal endoscopic microsurgery (TEM). A: normal rectal wall and mesorectal tissue; $\mathbf{B}$ : intact rectal wall with fibrosis; C: interrupted rectal wall with mass effect; $\mathbf{D}$ : oedema of rectal wall as a result of chemoradiation $(*)$; $\mathbf{E}$ : spicular fibrosis in the mesorectal tissue and extending to the MRF; $\mathbf{F}$ : fibrosis into mesorectal tissue with massive spread to the MRF

\section{Results}

\section{Demographics}

Eighty-one patients were included, 53 (65\%) underwent TEM as the primary treatment and $28(35 \%)$ underwent a TEM after neoadjuvant CRT. One of the patients had adjuvant CRT because of suspicious lateral nodes on MRI after TEM. Baseline characteristics are shown in Table 2. The median follow-up of the patients without recurrence as measured from the date of primary surgery was 50.5 months (range: 16-113 months). The median number of follow-up MRIs per patient was 3 (range 1-9), with a total number of 293 MRIs available for this study. 203/293 (69\%) MRIs were performed with a DWIsequence. Six MRIs (in two patients) were excluded from the evaluation because of inadequate visualization of the former tumour location $(n=5)$ or artefacts $(n=1)$. So, in total 287 MRIs were available for evaluation, of which 203 had DWI (71\%).

Eighteen patients (22\%) developed a recurrence (11 luminal, two nodal, five had both a luminal and nodal recurrence). In five patients a recurrence was already seen at the first post-
Table 2 Characteristics of the 81 included patients

Characteristic No recurrence $(n=63)$ Recurrence $(n=18)$ Total $(n=81)$

\begin{tabular}{llcc}
\hline $\begin{array}{l}\text { Age }(\mathrm{y})^{*} \\
\text { Mean }\end{array}$ & 64 & 64 & 64 \\
SD & \pm 11 & \pm 10 & \pm 10 \\
Sex & & & \\
Male & $47(74.6 \%)$ & $11(61.1 \%)$ & $58(71.6 \%)$ \\
Female & $16(25.4 \%)$ & $7(38.9 \%)$ & $23(28.4 \%)$ \\
Tumour stage & & & \\
(y)pT0 & $19(30.2 \%)$ & $3(16.7 \%)$ & $22(27.2 \%)$ \\
(y)pTis & $1(1.6 \%)$ & 0 & $1(1.2 \%)$ \\
(y)pT1 & $27(42.9 \%)$ & $9(50.0 \%)$ & $36(44.4 \%)$ \\
(y)pT2 & $13(20.6 \%)$ & $6(33.3 \%)$ & $19(23.5 \%)$ \\
(y)pT3 & $3(4.7 \%)$ & & $3(3.7 \%)$
\end{tabular}

18 patients had a local recurrence (11: luminal, 2 nodal and 5 both luminal and nodal)

* Age at time of transanal endoscopic microsurgery (TEM) 
TEM MRI. The median size of recurrences on MRI was $25 \mathrm{~mm}(9-130 \mathrm{~mm})$. Half of the recurrences had the largest maximal size in the axial plane, e.g. in the direction of the resection plane of the TEM.

\section{Diagnostic performance}

\section{Luminal recurrence}

Based on all MRI exams, AUCs for luminal recurrence detection on standard T2W-MRI was 0.72 (95\% CI: 0.54-0.89) for reader 1 and 0.80 (95\% CI: 0.64-0.96) for reader 2 . AUC for detection of a luminal recurrence on DWI was 0.70 (95\% CI: $0.53-0.88$ ) for reader 1 and 0.89 (95\% CI: $0.76-1.00)$ for reader 2 .

For reader 1, addition of DWI to T2W-MRI increased performance compared to T2W-MRI for the first postoperative scan only, but not for the subsequent follow-up MRIs. For reader 2, addition of DWI increased performance both for the first postoperative MRI and for subsequent MRIs, by increasing the confidence of the reader. In 5/16 (31\%) luminal recurrences DWI detected the recurrence earlier than T2WMRI (Fig. 2). Confidence of the readers in assessing recurrence increased during follow-up (Appendix 2). All results are shown in Fig. 3 and Table 3.

\section{Predictive factors on MRI for luminal recurrence}

Appearance of intermediate signal of the rectal wall and mesorectal tissue were statistically significant predictive factors for local recurrence (Fig. 4) with odds ratios between $6.8(95 \%$ CI: 2.4-19.8, p<0.001) and 8.0 (95\% CI: 2.7-23.4, p<0.001). The results of the regression analyses are shown in Table 4.

\section{Nodal recurrence}

For nodal recurrence detection the AUC was 0.72 (95\% CI: $0.49-0.95)$ for reader 1 and 0.80 (95\% CI: $0.60-1.00)$ for reader 2 . The sensitivity of nodal recurrence detection on the first MRI is low for both readers, with a high specificity. An increase in AUC was seen during follow-up (Table 3).

\section{Interobserver agreement}

Interobserver agreement based on all MRIs was good for standard T2W-MRI for detecting luminal recurrence ( $\mathrm{k} 0.68)$ and for detecting nodal recurrence $(\kappa 0.71)$. Interobserver agreement was moderate for detecting luminal recurrence with DWI (k0.57). For both T2W-MRI and DWI, interobserver agreement increased during follow up (T2W-MRI luminal: к0.09 to $\kappa 0.78$; T2W-MRI nodal: $\kappa 0.36$ to $\kappa 0.84$; and DWI luminal: $\kappa 0.49$ to $\kappa 0.61)$.
Fig. 2 Detection of a recurrence on diffusion-weighted imaging (DWI), before it was visible on T2W-MRI. A: MRI 6 months after transanal endoscopic microsurgery (TEM): no signs of recurrence on $\mathrm{T} 2 \mathrm{~W}$, but small focus (arrowhead) of high signal on b1000-DWI. B: MRI 9 months after TEM: recurrence visible on both T2W- and DWI-MR (arrow)

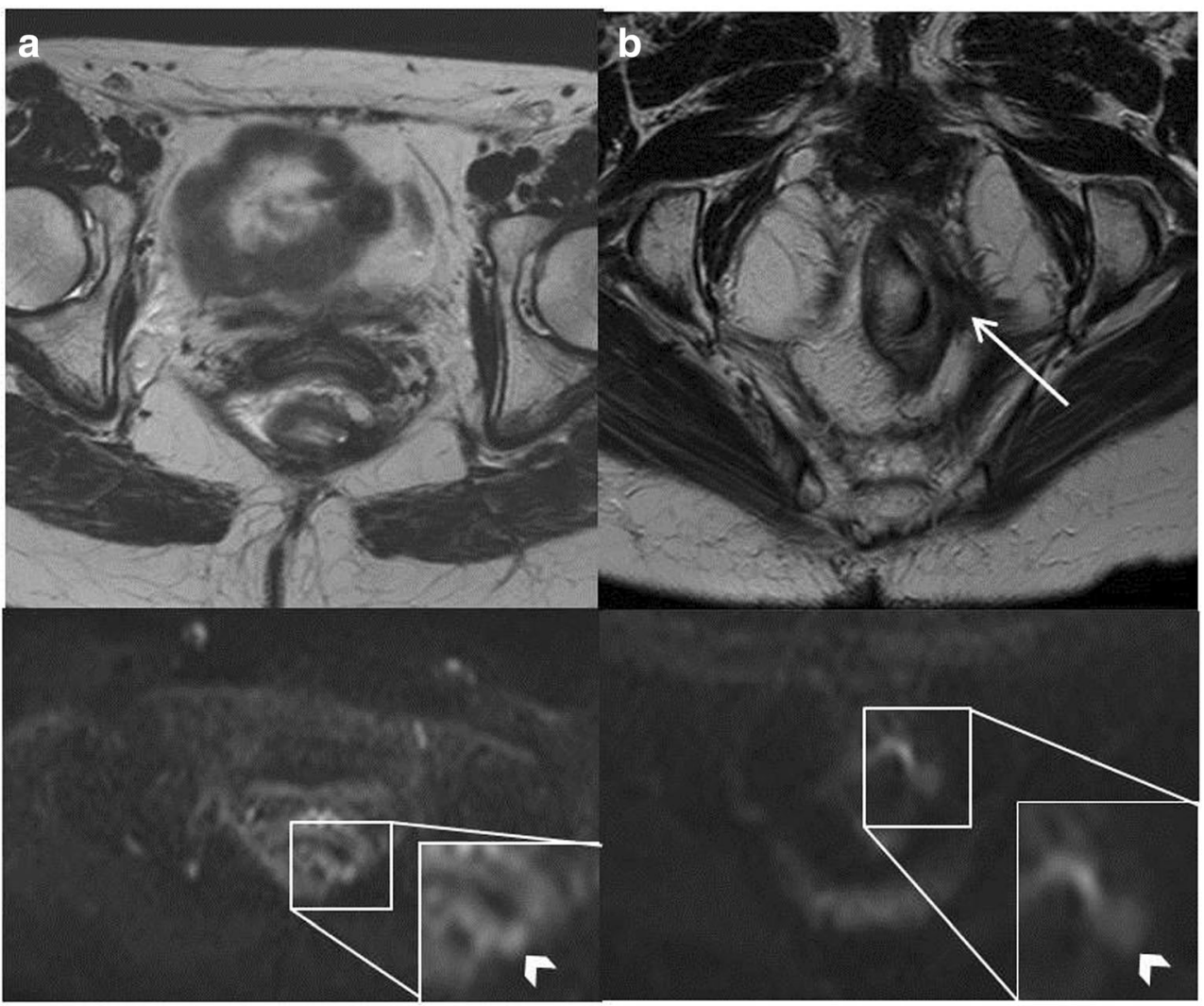


a

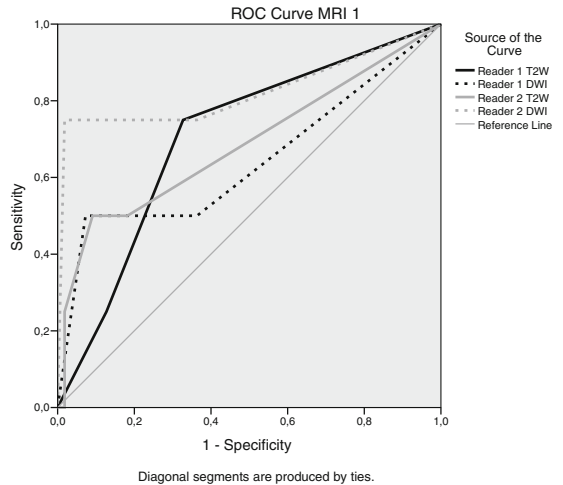

b

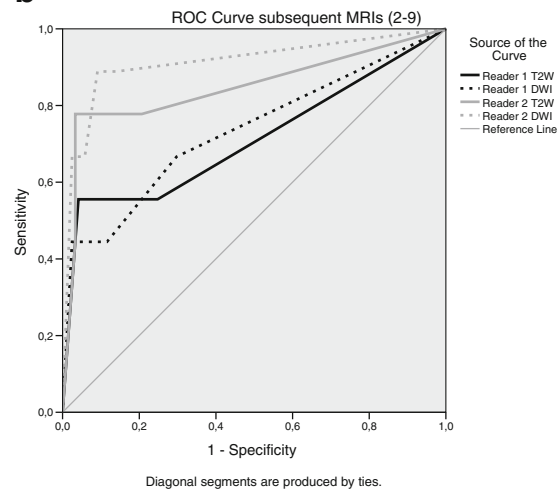

C

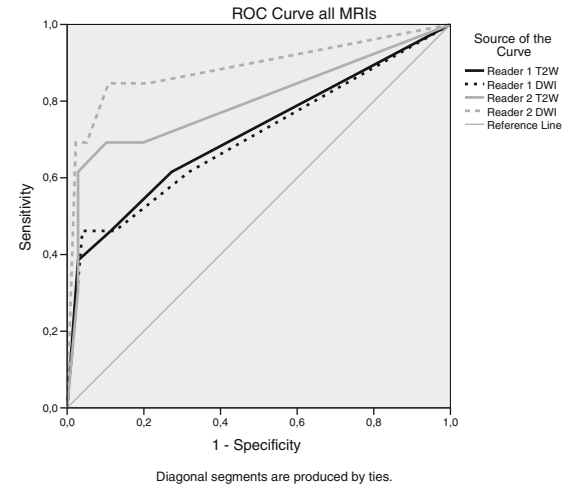

Fig. 3 Receiver operating characteristic (ROC) curves for the diagnostic performance for the detection of a luminal recurrence for standard T2W-MRI and DWI for both readers. A: ROC curve for first MRI; B: ROC curve for subsequent MRIs; C: ROC curve for all MRIs

\section{Differences in morphology between patients with and without chemoradiation}

There were some differences in morphology between patients with and without chemoradiation. Patients treated with neoadjuvant CRT had more fibrosis in the rectal wall, more oedema of the rectal wall, and a more intermediate signal of the mesorectum. These morphological differences were most prominent on the first and second MRI after TEM and the difference decreased after longer follow-up (Appendix 3).

\section{Discussion}

The present study shows that MRI is a feasible technique for follow-up after TEM for rectal cancer, both in a primary and in

Table 3 Diagnostic performance of local/nodal recurrence detection and AUC with $95 \%$ confidence intervals (CIs)

\begin{tabular}{|c|c|c|c|c|c|c|}
\hline & Reader 1 & & & Reader 2 & & \\
\hline Luminal T2W & All & First & Subsequent & All & First & Subsequent \\
\hline AUC & $0.72(0.54-0.89)$ & $0.71(0.45-0.96)$ & $0.71(0.59-0.93)$ & $0.80(0.64-0.96)$ & $0.69(0.36-1.00)$ & $0.85(0.67-1.00)$ \\
\hline Sensitivity & $50(27-73)$ & 0 & $67(36-88)$ & $62(37-83)$ & $25(0-90)$ & $75(43-92)$ \\
\hline Specificity & $96(90-98)$ & 100 & 94 (86-97) & $95(90-98)$ & $99(95-100)$ & $94(86-97)$ \\
\hline PPV & $40(24-59)$ & N/A & $40(24-58)$ & $44(26-62)$ & $50(3-97)$ & $43(25-63)$ \\
\hline \multirow[t]{2}{*}{ NPV } & 97 (94-99) & N/A & 98 (94-99) & 98 (95-99) & 96 (95-97) & $98(95-100)$ \\
\hline & Reader 1 & & & Reader 2 & & \\
\hline Luminal DWI & All & First & Subsequent & All & First & Subsequent \\
\hline AUC & $0.70(0.53-0.88)$ & $0.64(0.29-0.99)$ & $0.73(0.53-0.93)$ & $0.89(0.76-1.00)$ & $0.82(0.52-1.00)$ & $0.91(0.79-1.00)$ \\
\hline Sensitivity & $46(22-73)$ & $50(0-100)$ & $44(17-76)$ & $69(40-88)$ & $75(10-100)$ & $67(31-90)$ \\
\hline Specificity & 94 (89-97) & $93(83-100)$ & 95 (89-98) & $95(90-98)$ & $97(90-100)$ & 94 (88-97) \\
\hline PPV & $38(19-61)$ & $33(6-60)$ & 40 (19-65) & $50(29-71)$ & $60(19-79)$ & $46(27-67)$ \\
\hline \multirow[t]{2}{*}{ NPV } & $96(91-98)$ & 96 (93-99) & $96(90-98)$ & 98 (94-99) & $98(94-100)$ & 98 (92-99) \\
\hline & Reader 1 & & & Reader 2 & & \\
\hline Nodes & All & First & Subsequent & All & First & Subsequent \\
\hline AUC & $0.72(0.49-0.95)$ & $0.69(0.33-1.00)$ & $0.71(0.39-1.00)$ & $0.80(0.60-1.00)$ & $0.73(0.41-1.00)$ & $0.83(0.58-1.00)$ \\
\hline Sensitivity & $43(13-79)$ & 0 & $50(9-91)$ & $43(13-79)$ & $33(0-100)$ & $50(9-91)$ \\
\hline Specificity & 96 (89-99) & $99(95-100)$ & 95 (85-98) & 95 (85-99) & $94(85-100)$ & $96(81-99)$ \\
\hline PPV & $21(6-53)$ & $50(3-97)$ & $17(4-51)$ & $18(4-51)$ & $17(1-43)$ & $18(2-69)$ \\
\hline NPV & 99 (96-99) & 98 (96-99) & $99(96-100)$ & 99 (96-99) & $97(96-100)$ & $99(96-100)$ \\
\hline
\end{tabular}

$P P V=$ positive- predictive value;

$N P V=$ negative predictive value;

$A U C=$ area under the curve

$N / A=$ not applicable 
Fig. 4 Intermediate signal in rectal wall and mesorectum as an indicator of local recurrence
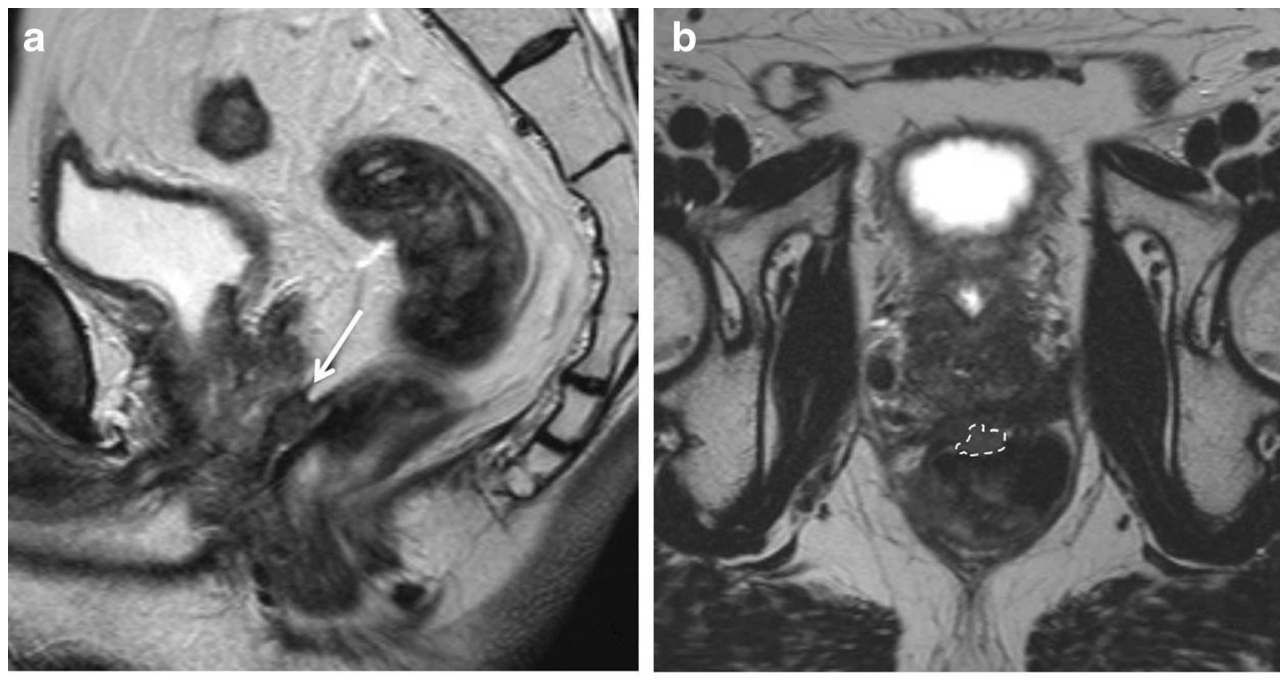

a post-CRT setting. Serial follow-up imaging allows readers to become more confident, shown by an increase in AUC and an increase in agreement for T2W-MRI and DWI when followup scans are compared to the first postoperative MRI scan. DWI can help in identifying recurrences earlier. Patients who had CRT showed more morphological abnormalities during follow-up after TEM than patients without CRT. At T2WMRI, intermediate signal intensity of the rectal wall was the most robust predictive factor for luminal recurrence. Identification of a nodal recurrence is more challenging, reflected by the low sensitivity for both readers.

There is limited evidence on follow-up after TEM for early rectal cancer and small tumours after chemoradiation. Studies published so far mainly focus on long-term outcome and used a heterogeneous strategy for follow-up, relying mainly on endoscopy [4, 23-25]. No studies have been published about the most suitable imaging modality and/or the most adequate follow-up schedule. The current results show that MRI can be considered as an imaging modality for follow-up after TEM, as an adjunct to the endoscopic follow-up. The first postoperative scan after TEM is difficult to interpret because of a heterogeneous signal at the TEM location, massive fibrosis and substantial oedema in the rectal wall and mesorectal fat, which leads to uncertainty in readers. This uncertainty is reflected in a relatively high number of equivocal scores (CL2), a lower interobserver agreement compared to follow-up MRIs and low sensitivities for both readers when evaluating the first postoperative MRI. When looking at follow-up scans, readers become more confident, probably because of the ability to compare with earlier scans. The one factor that helped both readers the most in identifying luminal

Table 4 Predictive factors of local recurrence

\begin{tabular}{|c|c|c|c|c|c|c|}
\hline \multirow[t]{2}{*}{ Predictive factors } & \multicolumn{2}{|l|}{ Reader 1} & \multicolumn{2}{|l|}{ Reader 2} & \multirow{2}{*}{$\begin{array}{l}\text { Proportion of specific } \\
\text { positive agreement }\end{array}$} & \multirow{2}{*}{$\begin{array}{l}\text { Proportion of specific } \\
\text { negative agreement }\end{array}$} \\
\hline & $p$-value & OR & $p$-value & OR & & \\
\hline \multicolumn{7}{|l|}{ All MRIs } \\
\hline Intermediate signal of the rectal wall & $<0.001 *$ & $6.8(2.4-19.8)$ & $<0.001 *$ & $8.0(2.7-23.4)$ & 0.277 & 0.908 \\
\hline High signal of the mesorectal tissue & 0.583 & $1.5(0.3-7.2)$ & 0.063 & $4.8(0.9-24.5)$ & 0.457 & 0.965 \\
\hline Intermediate signal of the mesorectal tissue & 0.864 & $0.9(0.2-4.0)$ & 0.093 & $2.6(0.9-7.8)$ & 0.419 & 0.898 \\
\hline \multicolumn{7}{|l|}{ First MRI } \\
\hline Intermediate signal of the rectal wall & 0.678 & $1.6(0.2-17.0)$ & 0.224 & $3.5(0.5-26.9)$ & 0.242 & 0.806 \\
\hline Fibrosis of the rectal wall & 0.463 & $2.4(0.2-23.8)$ & 0.647 & $1.7(0.2-17.3)$ & 0.735 & 0.594 \\
\hline \multicolumn{7}{|l|}{ Subsequent MRIs } \\
\hline Intermediate signal of the rectal wall & $<0.001 *$ & $16.6(4.6-60.1)$ & $<0.001 *$ & $12.1(3.3-44.3)$ & 0.313 & 0.942 \\
\hline Intermediate signal of the mesorectal tissue & 0.150 & $3.3(0.6-17.1)$ & $0.034 *$ & $4.0(1.1-14.3)$ & 0.256 & 0.922 \\
\hline High signal of the mesorectal tissue & 0.215 & $2.7(0.6-14.1)$ & 0.050 & $5.4(1.0-29.6)$ & 0.0667 & 0.979 \\
\hline
\end{tabular}

ORs (odds ratios) are reported with $95 \%$ confidence intervals;

* Statistically significant results 
Fig. 5 False-positive high signal on diffusion-weighted (DWI)MRI. A: High signal on b1000 DWI at first post-transanal endoscopic microsurgery (TEM) follow-up scan. B: 3 months later no signs of recurrence on $\mathrm{T} 2 \mathrm{~W}$ and DWI-MRI. The patient remained recurrence free during follow-up

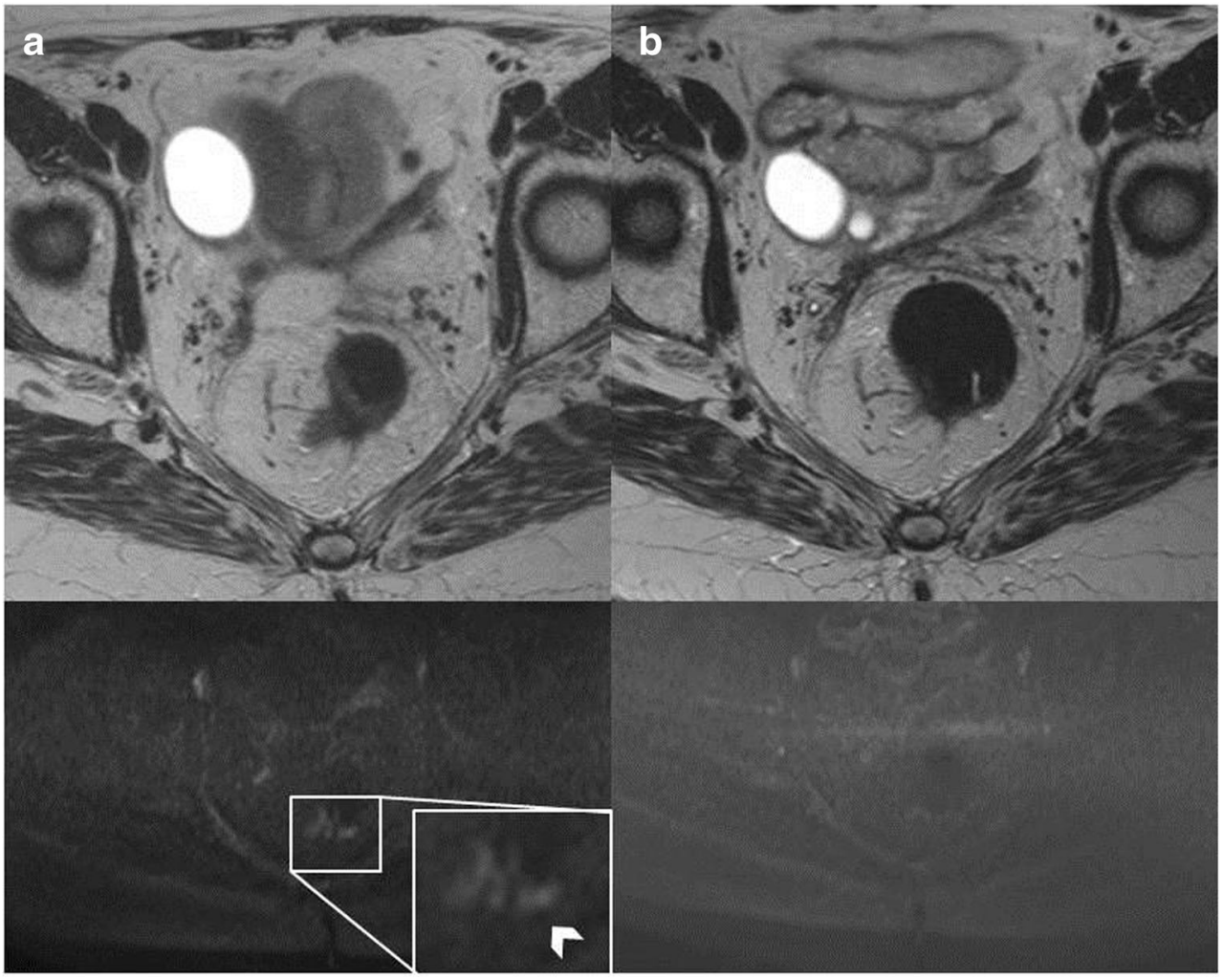

recurrences was the appearance of intermediate signal in the scar (Fig. 4). The appearance of intermediate signal in the dark fibrosis is rather easy to appreciate and the use of this sign can be of help when radiologists are evaluating post-TEM MRI in clinical practice. Strikingly, at the first postoperative MRI at 3 months after TEM five recurrences were already found. This finding points out the need for early imaging of the TEM scar in order not to miss early recurrences and to furthermore provide a baseline scan to compare with during further follow-up.

We found that DWI is helpful in the follow-up after TEM. Overall, DWI outperforms T2W-MRI for the detection of luminal recurrences. At the first postoperative MRI, DWI was more accurate compared to T2-weighted MRI, suggesting that DWI is less influenced by post-TEM changes, which is supported by the higher interobserver agreement at the first postoperative MRI for DWI compared to T2W-MRI. Addition of DWI mainly led to an increase in sensitivity compared to T2W-MRI when evaluating the first postoperative MRI, which leads to a lower risk of missing an early luminal recurrence. Also, DWI could identify a recurrence earlier during follow-up than T2W-MRI in several patients (Fig. 2), where appearance of diffusion restriction was noted before changes on T2W-MRI were seen. Probably, DWI helps in
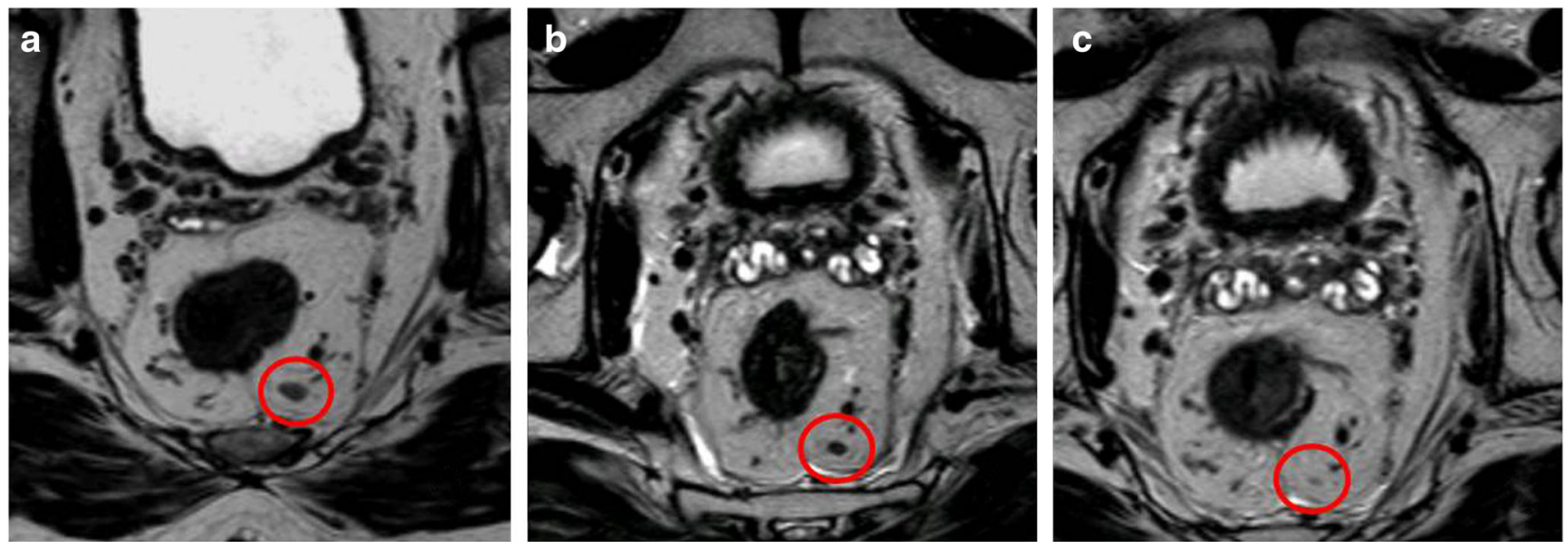

Fig. 6 Reactive nodes. A: MRI post-transanal endoscopic microsurgery (TEM). B: MRI 5 months post-TEM. C: MRI 8 months post-TEM. The major difference in post-TEM MRI is that at the first postoperative scan many reactive enlarged nodes are found which can confuse the radiologist 
differentiating tumour tissue from fibrosis, similar to its use in response evaluation of rectal cancer after chemoradiation, and therefore has a higher diagnostic performance than T2W-MRI only [26-28]. The higher sensitivity with DWI comes at the expense of a slightly lower specificity and a low positive-predictive value (PPV). This can be explained by the small foci of high signal that were sometimes found at post-TEM DWI, which disappeared during follow-up (Fig. 5) and can be misinterpreted as residual tumour or recurrence. Probably, these small foci of T2 shine through because of oedema, which - due to the small size of the foci - are difficult to appreciate on the ADC map.

Detection of a nodal recurrence remains a challenge - just as in primary staging of rectal cancer and given the very few nodal recurrences in this population it is difficult to draw any robust conclusions on nodal evaluation after TEM. The same difficulties regarding size and morphology apply during follow-up after TEM as when nodes are evaluated at primary staging and at restaging after chemoradiation. In our experience, the major difference in post-TEM MRI is that at the first postoperative scan many reactive enlarged nodes are found which can confuse the radiologist (Fig. 6).

Interobserver agreement was moderate to good for all modalities and outcomes. However, interobserver agreement was relatively low for the presence of predictive morphological features for luminal recurrence (e.g. appearance of intermediate signal in the scar/rectal wall). Given the low prevalence of recurrence we calculated the proportion of specific agreement for either the presence or absence of a morphological feature, rather than using Cohen's $\kappa$ (Table 4) [22]. This shows that mainly the agreement on presence of intermediate signal in the rectal wall and of the mesorectum is relatively low, even though it does increase during follow-up (from 0.24 at the first post-TEM MRI to 0.31 during follow-up). However, the fact that these features were predictive for luminal recurrence in the logistic regression analyses supports the fact that these features are reproducible and robust, even though agreement is relatively low. For all other morphological features agreement is moderate to excellent and, specifically, agreement on the absence of features is excellent.

\section{Limitations}

This study has several limitations. First, the study is retrospective and some of the patients underwent (neo)adjuvant chemoradiation, while others did not. However, we observed that the aspect of morphological changes is similar between the two groups, but in patients who had CRT changes were more profound and frequently encountered. After longer follow-up this difference decreased. Also, several patients refused salvage surgery, while based on histopathology salvage surgery was indicated. Second, follow-up was performed in two hospitals and MR protocols differed to some extent (Appendix 1). Third, only expert readers were involved, so it is unsure whether the results are applicable to the general reader. Last, there is no comparison with standard follow-up after TEM (endoscopy usually combined with CT/ERUS), so no recommendation can be made regarding cost-effectiveness of implementing MRI in the follow-up compared to regular follow-up.

\section{Conclusion and recommendations}

MRI (including DWI) is feasible for follow-up after TEM for rectal cancer. At the first postoperative scan the postoperative changes can be confusing, but during follow-up diagnostic performance and interobserver agreement increase. Therefore, we recommend using the first post-TEM MRI as a baseline scan for further follow-up. Because early recurrence can occur, the baseline scan can be performed approximately $4-6$ weeks after TEM. The factors on post-TEM MRI that are most suspicious for a recurrence are: (appearance of) intermediate signal and/or appearance of high signal at b1000 DWI-MRI in the scar tissue at the former tumour location. Nodal staging remains a challenge.

\section{Compliance with ethical standards}

Guarantor The scientific guarantor of this publication is M. Maas.

Conflict of interest The authors of this manuscript declare no relationships with any companies whose products or services may be related to the subject matter of the article.

Funding The authors state that this work has not received any funding.

Statistics and biometry Patty J. Nelemans kindly provided statistical advice for this manuscript.

Informed consent According to our country's national law, informed consent is not required for this study because of its retrospective nature.

Ethical approval According to our country's national law, institutional review board approval is not required for this study because of its retrospective nature.

Methodology

- Retrospective

- Multicentre study

\section{References}

1. Tytherleigh MG, Warren BF, Mortensen NJ (2008) Management of early rectal cancer. British J Surg 95:409-423

2. Borschitz T, Gockel I, Kiesslich R, Junginger T (2008) Oncological outcome after local excision of rectal carcinomas. Ann Surg Oncol 15:3101-3108

3. Verseveld M, de Graaf EJ, Verhoef C, van Meerten E, Punt CJ, de Hingh IH, et al. (2015) Chemoradiation therapy for rectal cancer in 
the distal rectum followed by organ-sparing transanal endoscopic microsurgery (CARTS study). The British J Surg

4. Lezoche E, Guerrieri M, Paganini AM, D'Ambrosio G, Baldarelli $M$, Lezoche $G$ et al (2005) Transanal endoscopic versus total mesorectal laparoscopic resections of T2-N0 low rectal cancers after neoadjuvant treatment: a prospective randomized trial with a 3-years minimum follow-up period. Surg Endosc 19:751-756

5. Restivo A, Zorcolo L, D'Alia G, Cocco F, Cossu A, Scintu F, et al. (2015) Risk of complications and long-term functional alterations after local excision of rectal tumors with transanal endoscopic microsurgery (TEM). Int J Colorectal Dis

6. Serra-Aracil X, Vallverdu H, Bombardo-Junca J, Pericay-Pijaume C, Urgelles-Bosch J, Navarro-Soto S (2008) Long-term follow-up of local rectal cancer surgery by transanal endoscopic microsurgery. World J Surg 32:1162-1167

7. Steinhagen E, Chang G, Guillem JG (2011) Initial experience with transanal endoscopic microsurgery: the need for understanding the limitations. J Gastrointest Surg : Off J Soc Surg Alimentary Tract 15:958-962

8. Buess G (1993) Review: transanal endoscopic microsurgery (TEM). J R Coll Surg Edinb 38:239-245

9. Allaix ME, Arezzo A, Caldart M, Festa F, Morino M (2009) Transanal endoscopic microsurgery for rectal neoplasms: experience of 300 consecutive cases. Dis Colon Rectum 52:1831-1836

10. De Graaf EJ, Doornebosch PG, Tollenaar RA, Meershoek-Klein Kranenbarg E, de Boer AC, Bekkering FC et al (2009) Transanal endoscopic microsurgery versus total mesorectal excision of T1 rectal adenocarcinomas with curative intention. Eur J Surg Oncol $35: 1280-1285$

11. Lebedyev A, Tulchinsky H, Rabau M, Klausner JM, Krausz M, Duek SD (2009) Long-term results of local excision for T1 rectal carcinoma: the experience of two colorectal units. Techn Coloproctol 13:231-236

12. Junginger T, Goenner U, Hitzler M, Trinh TT, Heintz A, Wollschlaeger D et al (2016) Long-term oncologic outcome after transanal endoscopic microsurgery for rectal carcinoma. Dis Colon Rectum 59:8-15

13. Perez RO, Habr-Gama A, Sao Juliao GP, Proscurshim I, Fernandez LM, de Azevedo RU et al (2016) Transanal Endoscopic Microsurgery (TEM) following neoadjuvant chemoradiation for rectal cancer: outcomes of salvage resection for local recurrence. Ann Surg Oncol 23:1143-1148

14. Burdan F, Sudol-Szopinska I, Staroslawska E, Kolodziejczak M, Klepacz R, Mocarska A et al (2015) Magnetic resonance imaging and endorectal ultrasound for diagnosis of rectal lesions. Eur J Med Res 20:4
15. Engelen SM, Beets GL, Beets-Tan RG (2007) Role of preoperative local and distant staging in rectal cancer. Onkologie 30:141-145

16. Lambregts DM, Lahaye MJ, Heijnen LA, Martens MH, Maas M, Beets GL et al (2016) MRI and diffusion-weighted MRI to diagnose a local tumour regrowth during long-term follow-up of rectal cancer patients treated with organ preservation after chemoradiotherapy. Eur Radiol 26:2118-2125

17. Landelijke_Werkgroep_Gastro-Intestinale_Tumoren (2016) Landelijke Richtlijn Rectumcarcinoom (version 3.0). www.oncoline.nl

18. Maas M, Beets-Tan RG, Lambregts DM, Lammering G, Nelemans PJ, Engelen SM et al (2011) Wait-and-see policy for clinical complete responders after chemoradiation for rectal cancer. J Clin Oncol : Off J Am Soc Clin Oncol 29:4633-4640

19. Hanley JA, McNeil BJ (1983) A method of comparing the areas under receiver operating characteristic curves derived from the same cases. Radiology 148:839-843

20. Rogers WH (1993) Regression standard errors in clustered samples. Stata Tech Bull Rep 3:88-94

21. Cohen J (1968) Weighted kappa: nominal scale agreement with provision for scaled disagreement or partial credit. Psychol Bull 70:213-220

22. de Vet HC, Mokkink LB, Terwee CB, Hoekstra OS, Knol DL (2013) Clinicians are right not to like Cohen's kappa. BMJ 346:f2125

23. Guerrieri M, Gesuita R, Ghiselli R, Lezoche G, Budassi A, Baldarelli M (2014) Treatment of rectal cancer by transanal endoscopic microsurgery: experience with 425 patients. World J Gastroenterol : WJG 20:9556-9563

24. Doornebosch PG, Ferenschild FT, de Wilt JH, Dawson I, Tetteroo GW, de Graaf EJ (2010) Treatment of recurrence after transanal endoscopic microsurgery (TEM) for T1 rectal cancer. Dis Colon Rectum 53:1234-1239

25. Sylla P, Rattner DW, Delgado S, Lacy AM (2010) NOTES transanal rectal cancer resection using transanal endoscopic microsurgery and laparoscopic assistance. Surg Endosc 24:1205-1210

26. van der Paardt MP, Zagers MB, Beets-Tan RG, Stoker J, Bipat S (2013) Patients who undergo preoperative chemoradiotherapy for locally advanced rectal cancer restaged by using diagnostic MR imaging: a systematic review and meta-analysis. Radiology 269:101-112

27. Lambregts DM, Vandecaveye V, Barbaro B, Bakers FC, Lambrecht M, Maas M et al (2011) Diffusion-weighted MRI for selection of complete responders after chemoradiation for locally advanced rectal cancer: a multicenter study. Ann Surg Oncol 18:2224-2231

28. Lambregts DM, Maas M, Bakers FC, Cappendijk VC, Lammering G, Beets GL et al (2011) Long-term follow-up features on rectal MRI during a wait-and-see approach after a clinical complete response in patients with rectal cancer treated with chemoradiotherapy. Dis Colon Rectum 54:1521-1528 